\title{
An Original Tribometer to Analyze the Behavior of Abrasive Grains in the Grinding Process
}

\author{
Leire Godino * (i), Iñigo Pombo, Jose Antonio Sanchez and Borja Izquierdo \\ Faculty of Engineering Bilbao, University of the Basque Country (UPV/EHU), Plaza Ingeniero Torres Quevedo, \\ 1, 48013 Bilbao, Spain; inigo.pombo@ehu.eus (I.P.); joseantonio.sanchez@ehu.eus (J.A.S.); \\ borja.izquierdo@ehu.eus (B.I.) \\ * Correspondence: leire.godino@ehu.eus; Tel.: +34-946017347
}

Received: 10 July 2018; Accepted: 18 July 2018; Published: 20 July 2018

\begin{abstract}
Manufacturing of grinding wheels is continuously adapting to new industrial requirements. New abrasives and new wheel configurations, together with wheel wear control allow for grinding process optimization. However, the wear behavior of the new abrasive materials is not usually studied from a scientific point of view due to the difficulty to control and monitor all the variables affecting the tribochemical wear mechanisms. In this work, an original design of pin-on-disk tribometer is developed in a CNC (Computer Numerical Control) grinding machine. An Alumina grinding wheel with special characteristics is employed and two types of abrasive are compared: White Fused Alumina (WFA) and Sol-Gel Alumina (SG). The implemented tribometer reaches sliding speeds of between 20 and $30 \mathrm{~m} / \mathrm{s}$ and real contact pressures up to $190 \mathrm{MPa}$. The results show that the wear behavior of the abrasive grains is strongly influenced by their crystallographic structure and the tribometer appears to be a very good tool for characterizing the wear mechanisms of grinding wheels, depending on the abrasive grains.
\end{abstract}

Keywords: grinding; wheel wear; wear flat; precision; tribometry; pin-on-disk

\section{Introduction}

New developments in grinding wheels have allowed for more specific applications of the grinding process in different sectors of the industry, including the automotive and aeronautical sectors. However, the grinding process is still widely used as a finishing process [1]. The high-quality surfaces and close tolerances achieved during this manufacturing process depend mainly on the precision and rigidity of the grinding machine, the grinding parameters, and the grinding wheel [2]. Moreover, improvements in grinding wheels and abrasive grains imply the need to characterize the behavior of new abrasives under grinding conditions. In addition to the innovations in superabrasives, the most important breakthrough with regard to alumina is the microcrystalline sintered structure studied by Norton Company that became part of the Saint-Gobain group in 1990, SG ${ }^{\mathrm{TM}}$. These abrasive grains are characterized by a self-sharpening capacity due to randomly orientated micro-crystals of $0.1-5 \mu \mathrm{m}$ in size [3]. Currently, these continuous improvements lead to variations in grain shapes, long cylinders or triangle shapes (among others), with the aim of enhancing cutting efficiency and minimizing abrasive grain wear [3,4]. However, there is a lack of knowledge regarding the behavior of abrasive grains under heavy grinding conditions.

The main types of wear found on grinding wheels are abrasive grain loss (due to the fracture of the bond), abrasive grain fracture, and wear flat. Furthermore, abrasive grains are subjected to wear under different mechanisms such as abrasion, adhesion, or chemical reactions, and the combination of these mechanisms leads to a given wear type [5]. Grinding wheel topography presents a direct influence on the quality of workpiece and depends on the specification of the designed grinding wheel, 
dressing parameters, and the state of wear of the wheel surface [6]. Wheel wear promotes dimensional and geometrical errors in the workpiece. Furthermore, variations on the wheel surface due to wheel wear imply variations in contact conditions between grinding wheel and ground surface. Changes in contact conditions make changes in the surface roughness of the workpiece.

Of the different types of wear, wear flat presents one of the most negative consequences for the workpiece surface. The appearance and evolution of wear flat imply an increase in the contact area of abrasive grains, and consequently an increase in power and specific energy with the contact area. The high temperatures reached on contact leads to thermal damage in the workpiece, along with a loss of dimensional accuracy. Due to variations in the contact area, contact conditions also vary during the process, making the control of the grinding process difficult. Wheel wear (particularly wear flat) represents one of the chief disadvantages of using the grinding process. From both a research and an industrial point of view, grinding process users are worried about this problem and hence their efforts are focused on minimizing the appearance of wear flat.

The measurement of the wear flat area has also been the focus of recent work concerning the analysis of grinding wheel wear $[7,8]$. The most common techniques to measure the topography are non-contact techniques, particularly confocal microscopy. A functional surface of the grinding wheel is characterized using a 3D parametrical study based on ISO 25178 standard. Height parameters, functional parameters, and the Abbott-Firestone curve are the most significant parameters for measuring wear on the grinding wheel surface [6]. Furthermore, there is a statistical method to evaluate the most significant parameter for comparing two states, which was developed by Leach [9]. This method is suitable for comparing new and worn states of abrasive wheels.

The tribochemical nature of wear flat raises the need to address this issue, mainly from the perspective of studying the grinding process or implementing tribological tests, particularly pin-on-disk tests. With respect to experimental grinding tests, studies have been carried out to examine the influence of grinding parameters on wear evolution, and hence, on the efficiency of the process $[8,10,11]$. In this case, the main challenge of studying a specific type of wheel wear is in terms of isolating this from other types of wear. There are a few studies that have attempted to address this problem $[12,13]$. For instance, Malkin carried out the first study of wear flat evolution, showing friction coefficient variation during the contact due to an increase in normal force, showing also a considerable increase of \%A with the force and with the specific removal material [10]. In this study, not only wear flat was found to occur, but also other kinds of simultaneous wear, with the evolution of wear flat being interrupted. Nadolny [11] conducted internal grinding experiments, showing not only wear flat on the abrasive wheel surface but also other kinds of wear. The aim of this study was to compare the wear behavior of different wheel configurations, varying the bond. Wear flat generation is studied on both alumina wheels studied and cBN abrasive grains [8]. The latter study examined the effect of wear flat on power consumption along with the effect of wheel conditioning. In general, the main challenge of studying a specific type of wear, not only wear flat, is the isolation from the other types. In order to characterize grain pull out of cBN wheels, Yu [12] implemented specific tests on a designed device and obtained values of forces required to pull out the grain.

With respect to wear flat, in previous work [13], grinding tests have been conducted to isolate wear flat from other kinds of wear. The specific design of the grinding wheel allows for the isolation and finishing grinding parameters that encourage rubbing and ploughing mechanisms in order to promote the generation of wear flat. In this work, wear flat behavior is compared between WFA and SG. The \%A generated in the case of SG is approximately 23\% higher than WFA; however, grinding forces are maintained at an approximately constant level. With regard to wheel topography, the SG surface presents a smoother appearance. The amount of third body attached to the flat grains is higher, indicating the importance of the tribochemical effect on the generation of wear flat. This issue requires a deeper analysis, with the need for an exhaustive control of contact conditions despite the randomness of wheel topography. In addition, single grain studies are the most common to avoid the randomness of the wheel topography and to control the grinding process. These tests correlate real 
contact conditions, grinding forces and cutting mechanisms. Furthermore, these studies are carried out both in experimental tests and modeling studies [14,15]. However, on the basis of the current evidence, it is not possible to extrapolate the results from a unique abrasive grain to a complete grinding wheel, because the interactions between the surrounding abrasive grains can have an impact on the results.

From a tribological point of view, the contact between alumina and steel is widely studied. Ravikiran examined alumina-steel contact at $12 \mathrm{~m} / \mathrm{s}$ and $50 \mathrm{MPa}$ [16], finding that a third body adhered to both bodies in contact, promoting variations in friction coefficients. Under conditions that closely resemble those of grinding, whilst also carrying out the tests on a pin-on-disk tribometer, Klocke [17] reached pressures of $0.5-1.5 \mathrm{GPa}$, as observed in the grinding process. However, the sliding speed was of $2 \mathrm{~m} / \mathrm{s}$, and thus temperatures were reached that cannot be extrapolated to grinding results. Furthermore, when conducting pin-on-disk tests, the thermal cycle of alumina is not taken into account. In the case of grinding tests, abrasive grains show intermittent contact with the steel; however, when using alumina pin and steel disk, the alumina slides continuously without any abrasive grain contact.

The present study aimed to address the lack of knowledge gained from previous work by applying real grinding conditions to a pin-on-disk tribometer. A discontinuous contact between alumina and steel is reproduced, changing the roles of pin and disk. In this case, a real alumina grinding wheel is used as a disk, following previous studies carried out to characterize wear flat during grinding tests [13]. A comparison of the wear behavior of WFA and SG alumina disks is conducted. Real randomness of the topography is used, allowing the cooling of abrasive grains and reproducing the thermal cycle that is suffered by the alumina during grinding. Furthermore, the simulated contact conditions are close to the grinding parameters, using a sliding speed of $30 \mathrm{~m} / \mathrm{s}$ and controlling the contact area to reach high contact pressures. Finally, to advance knowledge of the wear flat phenomenon and the wear mechanisms that take place during contact, a deep analysis of worn alumina is carried out through a 3D parametrical study of disk topography. Taking into account these facts, it is possible to extrapolate pin-on-disk tribometer wear results to a real grinding process.

\section{Materials and Methods}

The tribological contact between alumina and steel is studied in order to characterize alumina wear under grinding conditions. The first issue to deal with is the design of the pin-on-disk tribometer which allows for reproducing grinding conditions and controlling real contact. The designed pin-on-disk tribometer consists of a double-acting pneumatic cylinder. This device is activated by a selector valve, switch, and a pressure gauge that allows for flow regulation. The pneumatic control set up is displayed in Figure 1a. The theoretical maximum force of the cylinder is of $8500 \mathrm{~N}$ with a pneumatic pressure of 7 bar, which is the maximum pneumatic pressure of the installation. On the cylinder plunger, a pin holder with guide system is assembled to avoid rotation of the pin due to the tangential force. The pneumatic system is assembled on the surface of the grinding machine in order to achieve the grinding cutting speed and sliding speed on the tribometer. 


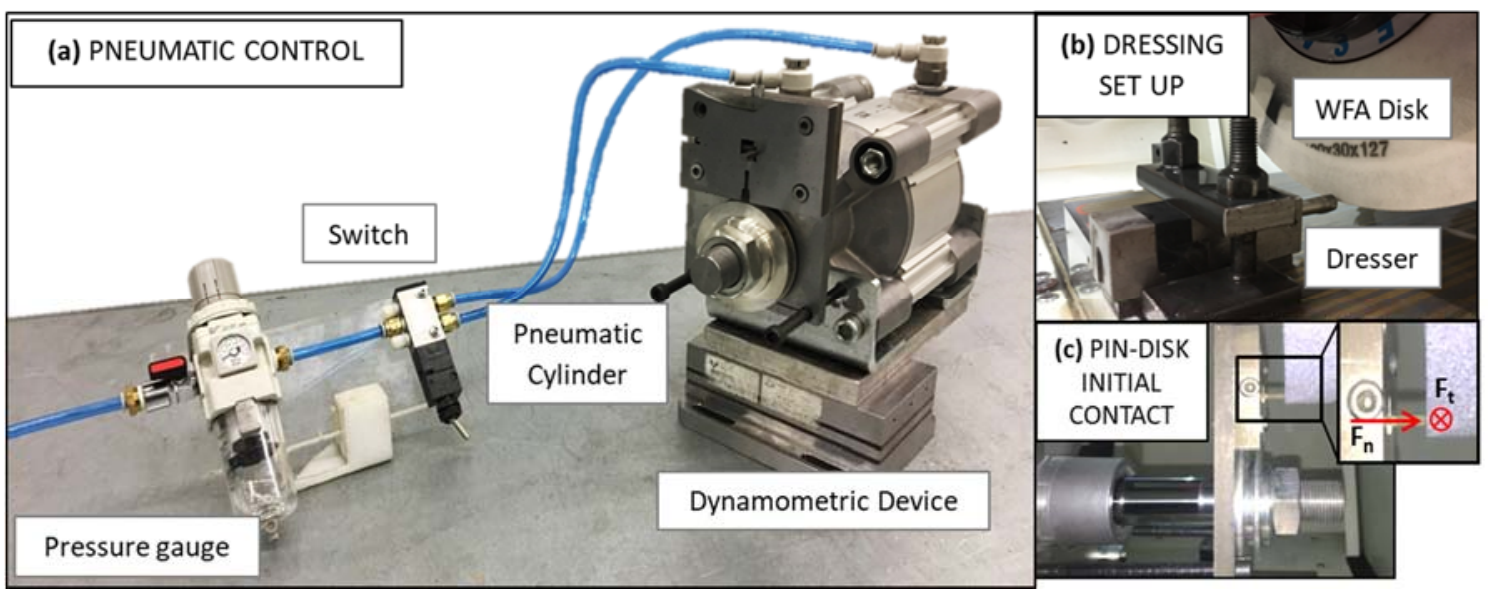

Figure 1. (a) Set up of pneumatic control of pin-on-disk, (b) dressing set up of vertical surface of the wheel and (c) initial contact between pin and disk on the vertical and conditioned wheel surface.

With the purpose of achieving a discontinuous contact of alumina and thus reproducing the thermal cycle of abrasive grains, two requisites are taken into account. Firstly, pin and disk roles are changed. Generally, pin material is the material under examination. However, in this study, alumina is analyzed and an alumina disk is employed. Secondly, to take into account not only the material but also the abrasive grain properties and wheel configuration, a real grinding wheel is used as a disk, and the tests are carried out on the frontal flat face of the grinding wheel as shown in Figure 1b,c. In order to develop previous work [13], in which wear flat is studied during grinding tests, in this study the same abrasive grains of the grinding wheels are employed, WFA and SG. In both designed grinding wheels, only the crystalline structure of abrasive grains is changed. The bond is the same for WFA and SG wheels, in order to avoid the influence in the results of other factors. Table 1 lists the main features of the experimental work.

Table 1. Set up of pin-on-disk tests and surface analysis.

\begin{tabular}{cc}
\hline Set up Instruments and Materials & Specification \\
\hline Surface Grinding Machine & Blohm Orbit CNC 36 (United Grinding, Hamburg, Germany) \\
Pneumatic Control & $\begin{array}{c}\text { Pressure gauge with flow regulation, } 3 \text { position switch and pneumatic } \\
\text { cylinder } \varnothing 125-50 \mathrm{~mm}\left(\mathrm{~F}_{\max }=12,000 \mathrm{~N}\right)\end{array}$ \\
Wheel Specification & $54 \mathrm{R} 6 \mathrm{~V} 89$, grain size $300 \mu \mathrm{m}$ \\
Wheel Dimensions & $400 \times 20 \times 127 \mathrm{~mm}$ \\
Workpiece Material & Tempered AISI D2 $60 \pm 2 \mathrm{HRC}$ \\
Pin Dimensions & $3 \times 5 \times 25 \mathrm{~mm}$ \\
Dynamometric Device & Kistler 9257B (Kistler Group, Winterthur, Switzerland) \\
& Confocal microscope Leica DCM3D ${ }^{\circledR}$ (Leica microsystems AG, Wetzlar, \\
Microscopes & Germany) magnification $10 \times / 0.3$ and LeicaMap ${ }^{\circledR}$ (Leica microsystems \\
& AG, Wetzlar, Germany) to image processing \\
\hline
\end{tabular}

The second issue that is addressed is related to contact pressure. The real contact pressure is controlled and values closest to real grinding process have to be achieved, about 1.5 GPa. Hardened steel pins are set by WEDM to ensure a complete contact with the disk. The pin dimensions are displayed in Table 1 . The area must be sufficiently large to avoid pin breakage and small enough to increase the contact pressure, with $15 \mathrm{~mm}^{2}$ being the most suitable pin contact area. The close structure of the wheels and fine dressing parameters allow for controlling and increasing the real contact area. In Figure $1 b$ the dressing set up is shown. The dresser tool of a single point diamond is assembled to dress the vertical surface of the disk. A dresser speed of $v_{d}=60 \mathrm{~mm} / \mathrm{min}$ and dressing depth $a_{d}=5 \mu \mathrm{m}$ 
are employed. However, due to the random wheel surface, the real contact area is smaller than the apparent contact area, as in the grinding process.

To quantify the real contact area, the just dressed wheel topography is measured using confocal microscopy. To analyze the topographies, a reference plane is first determined using the Abbot-Firestone curve. The reference plane is the height from which the core roughness depth, $S_{k}$, is taken into account. In Figure 2 the steps used to establish the reference plane are shown. Once the reference plane is defined; parallel planes are conducted at different depths of the analysed 3D surface. Furthermore, after conducting the pin-on-disk tests, the worn alumina is measured. The depth of worn alumina establishes the plane at which the contact area is quantified, which allows for obtaining the real contact area for each studied surface, and hence real contact pressure.

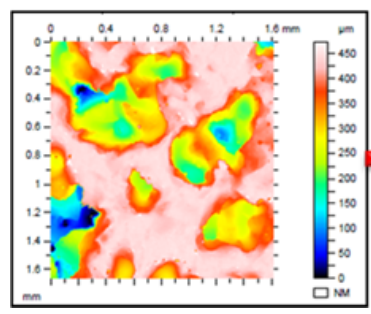

(a)

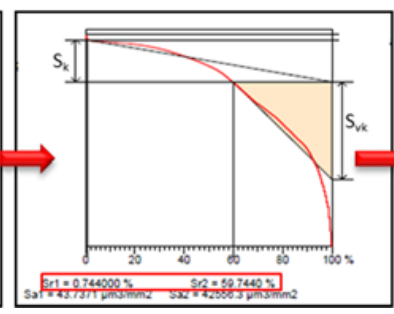

(b)

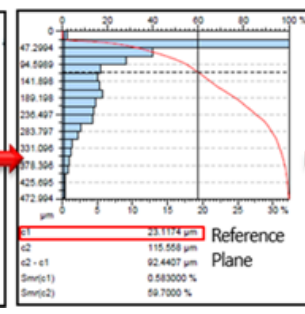

(c)

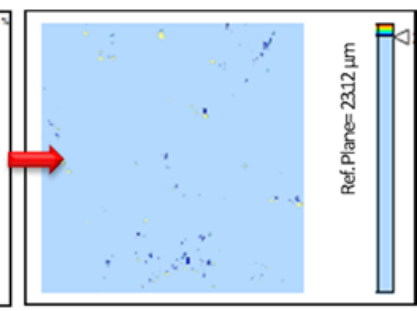

(d)

Figure 2. Steps to achieve the reference plane of each conditioned wheel surface. (a) Surface topography, (b) Abbot-Firestone curve and its corresponding functional parameters, (c) Abbot-Firestone curve and material distribution and (d) reference plane showing sliced material.

Following wheel and pin conditioning, pin-on-disk tests were carried out. Sliding speed, pneumatic pressure and theoretical force are varied in order to observe the influence of each parameter. Table 2 displays the complete battery of experimental tests. During the tests forces are measured using a dynamometric device. The contact time of the tests is limited by the length of the pins, $25 \mathrm{~mm}$. Due to the slenderness of the pins, it is not possible to increase the length within the designed area.

Table 2. Pin-on-disk test parameters.

\begin{tabular}{|c|c|c|c|c|}
\hline \multirow{2}{*}{\multicolumn{2}{|c|}{ Tests Parameters }} & \multicolumn{3}{|c|}{ Pneumatic Pressure/Theoretical Force } \\
\hline & & $0.6 \mathrm{MPa} / 7200 \mathrm{~N}$ & $0.7 \mathrm{MPa} / 8400 \mathrm{~N}$ & $0.8 \mathrm{MPa} / 9600 \mathrm{~N}$ \\
\hline \multirow{3}{*}{ Sliding Speed $v_{S}$} & $20 \mathrm{~m} / \mathrm{s}$ & $1 \mathrm{a}$ & $2 a$ & $3 a$ \\
\hline & $25 \mathrm{~m} / \mathrm{s}$ & $1 b$ & $2 b$ & $3 b$ \\
\hline & $30 \mathrm{~m} / \mathrm{s}$ & $1 c$ & $2 c$ & $3 c$ \\
\hline
\end{tabular}

Following the pin-on-disk tests, alumina wear was characterized. Confocal microscopy was used to analyze the wear generated on the disk. The measured area $(x, y)$ is of $6.69 \times 1.77 \mathrm{~mm}^{2}$ and $z$ scan range of $600 \mu \mathrm{m}$, with a resolution of $4 \mu \mathrm{m}$. In addition, monochromatic light was used and the disk was covered with graphite in order to minimize the brightness of the images.

On the one hand the depth of groove generated in the disk surface is measured and on the other hand functional parameters are analyzed. In Figure 3a 3D image reveals the generated groove in alumina. Each test is measured in six different sections equally spaced along the wheel. The mean value of the depth of groove is obtained for each test. In order to quantify the wear depth, for each digitalization 100 profiles are extracted and superimposed, as shown in Figure 3b. The upper line limiting all the profiles shows the shape of the groove. However, the quantification shown in Figure $3 \mathrm{c}$ is not easy because the brightness of abrasive grains generates the distortion of the profile. This upper profile is filtered using morphological filters. The morphological filters are widely used to analyze engineering surfaces, and are suitable for extracting geometrical features of surfaces such as the 
shape [18]. In this study, an alternate opening-closing sequence of filters is used for eliminating high and thin peaks and valleys. The structuring element employed to apply the morphological filter is a circular disk of $0.5 \mathrm{~mm}$ in diameter. In Figure $3 \mathrm{~d}$, the envelope line after filter application is shown. On this profile, the depth of groove is measured.
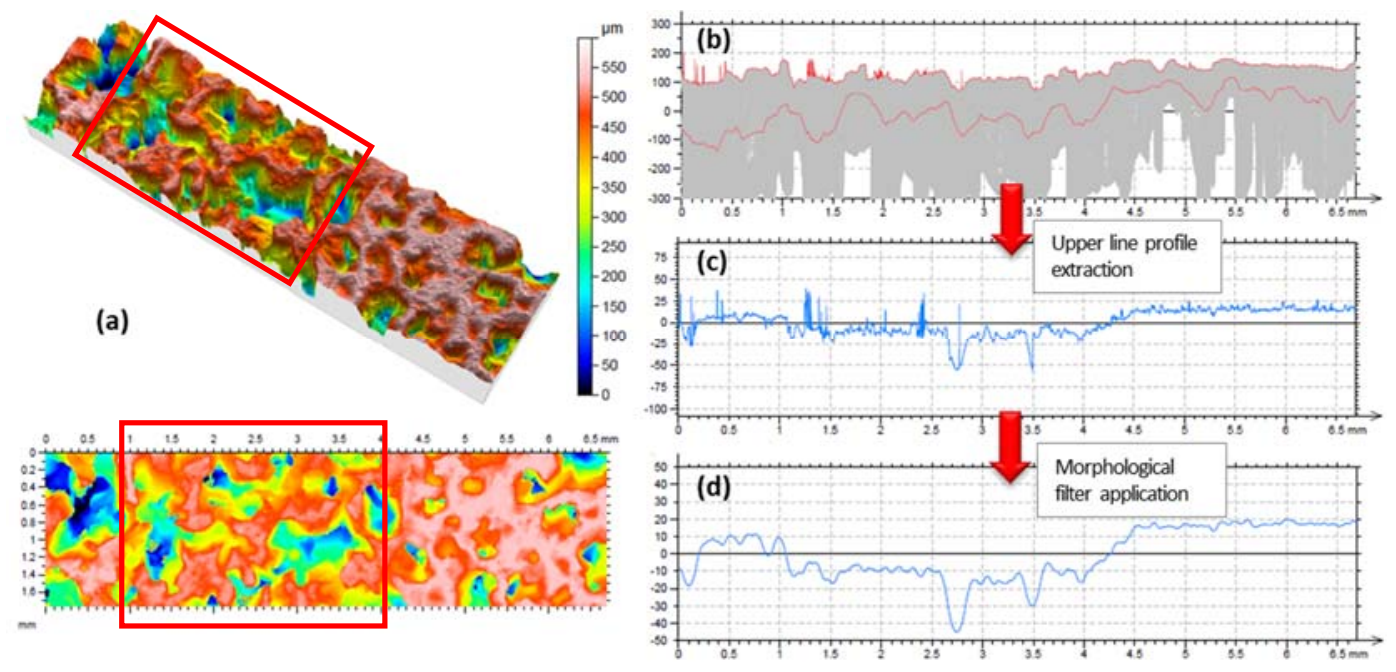

Figure 3. Wear depth quantification. (a) Surface digitalization, (b) Profiles superimposition, (c) Upper line extraction and (d) envelope line after morphological filter application.

Finally, following groove depth measurement, a functional roughness surface analysis was carried out. Worn and just dressed, new, alumina is studied, extracting from previous digitalization a sample of $2 \times 1.5 \mathrm{~mm}^{2}$. Functional parameters are used to compare the behavior of WFA and SG alumina under grinding contact conditions, which are exhaustively controlled. Also, through roughness parameters differences on new and worn states of each kind of alumina are revealed.

\section{Results and Discussion}

Pin-on-disk tests were conducted, varying the sliding speed and pneumatic pressure of the cylinder. Both normal and tangential forces (Figure 1) are higher to lower sliding speed. For WFA tests and a sliding speed of $20 \mathrm{~m} / \mathrm{s}$, the mean value of $F_{n}$ is $514 \mathrm{~N}$. However, for $30 \mathrm{~m} / \mathrm{s}$, a value of $455 \mathrm{~N}$ was reached. In contrast, the tendency of forces with pneumatic pressure variation is not shown, and normal force values vary from $490 \mathrm{~N}$ to $510 \mathrm{~N}$. This is due to the materials in contact and the heavy conditions of the tests. In Figure 4, the normal and tangential force of Test $1 \mathrm{a}$ is plotted, whilst the alumina steel contact time is also shown. The apparent small pin contact area together with high sliding speed promotes high temperatures on contact, softening hardened steel and increasing abrasive grain wear. Therefore, the contact time is very short-approximately $1.15 \mathrm{~s}$-which impedes the ability to reach theoretical force. That being the case, the studied cases do not present significant variations with pneumatic pressure. Similarly, the wear that occurs in $1.15 \mathrm{~s}$ is too high compared with the wear suffered during a real grinding process. 


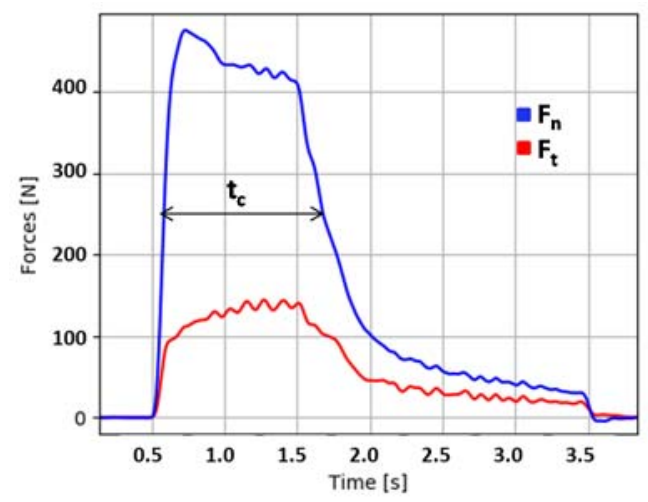

Figure 4. Normal and tangential force signals of test 1a for WFA.

From now, only sliding speed variation is taken into account to analyze pin-on-disk results. Each test is replicated three times. The mean value of the three tests for each sliding speed is obtained and results are analyzed according to $v_{s}$ and abrasive grain structure variation.

The main objective of this original design of pin-on-disk tests is to control real pressure and hence the real contact area between the alumina disk and steel pin. Therefore, once the tests have been conducted the next step is to quantify the real contact area through disk surface characterization. This contact occurs at the depth of disk wear, so before obtaining the real contact area the groove generated in the alumina must be quantified. These steps are followed for each test as it is shown in Figure 3. The mean value of groove depth for each abrasive grain structure and for each sliding speed is represented in Figure 5a.

(a) Disk depth wear

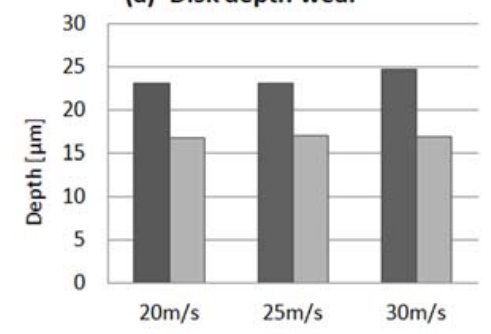

(b) $\mathrm{S}_{\mathrm{pk}}[\mu \mathrm{m}]$

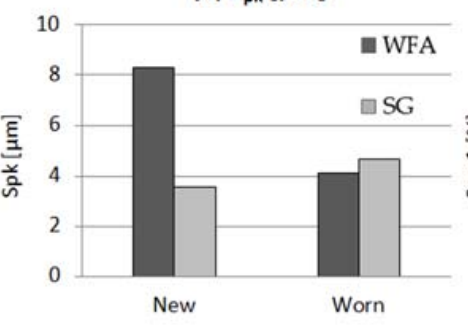

(c) $\mathrm{S}_{\mathrm{mr1}}[\%]$

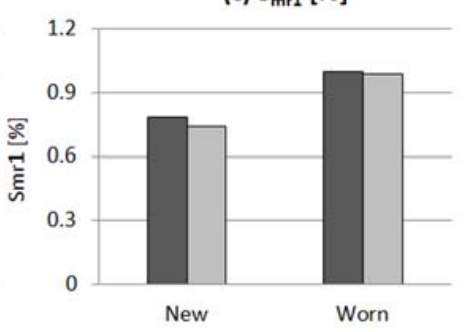

Figure 5. (a) Alumina groove depth, (b) Reduced peak height and (c) peak material proportion of new and worn alumina.

With regard to the influence of sliding speed on wear, very similar values are shown for the three speeds tested. Therefore, for $v_{s}$ range studied, there is no significant variation of depth wear. However, in relation to abrasive grain structure, a greater depth of groove is measured for WFA than for SG alumina. WFA presents a mean depth of $23 \mu \mathrm{m}$ while SG has a mean depth of $17 \mu \mathrm{m}$. Studied abrasive grain size is of $300 \mu \mathrm{m}$ and the depth of wear represents $7.67 \%$ for WFA and $5.67 \%$ in case of SG alumina of a total abrasive grain. So, linking alumina disk wear on pin-on-disk tribometer to abrasive grains wear during the grinding process confirms the lack of abrasive grain pull out. Furthermore, in the case of WFA, it can also be confirmed that the unique type of wear that occurred is wear flat. To affirm the existence of grain breakage on WFA, the depth of wear must be approximately $1 / 3$ of abrasive grain size, thus $100 \mu \mathrm{m}$. In contrast, this is not the case for SG alumina, because the size of the microcrystals is approximately $0.1-5 \mu \mathrm{m}$.

To identify each type of abrasive grain wear in tribological wear tests, a reduced peak height functional parameter and peak material proportion parameter are used. The values of these parameters are represented in Figure 5b,c. With regard to WFA, if just dressed and worn states are compared, higher values of $S_{p k}$ are achieved for new alumina, and so a rougher or sharp surface is obtained on 
dressed disk than on a worn part, and the height of the peaks is halved for worn alumina. Furthermore, the material proportion in the peaks increases to $20 \%$ for worn alumina. Therefore, wear flat is the wear type that occurs in WFA.

Analyzing SG alumina, $S_{p k}$ increases for new to worn by less than $25 \%$, and thus a sharper surface is obtained on worn alumina. With respect to $S_{m r 1}$, the same increase in the proportion of material is shown, maintaining the proportion between peaks and material increase and hence maintaining the surface characteristic. This fact implies that the sharpness of new and worn surfaces do not have variations. Therefore, the main wear type of SG alumina during pin-on-disk tests is the microfracture of abrasive grains, leading to shelf-sharpening. The conclusions reached regarding functional parameters are confirmed on the surfaces shown in Figure 6. 3D digitalized topographies and the envelope line of profiles after applying morphological filter show dissimilarities on the worn alumina. The groove generated after the tribological test is marked in red. A flatter surface is shown on worn WFA compared with worn SG, and greater peaks are plotted on the SG worn profile.

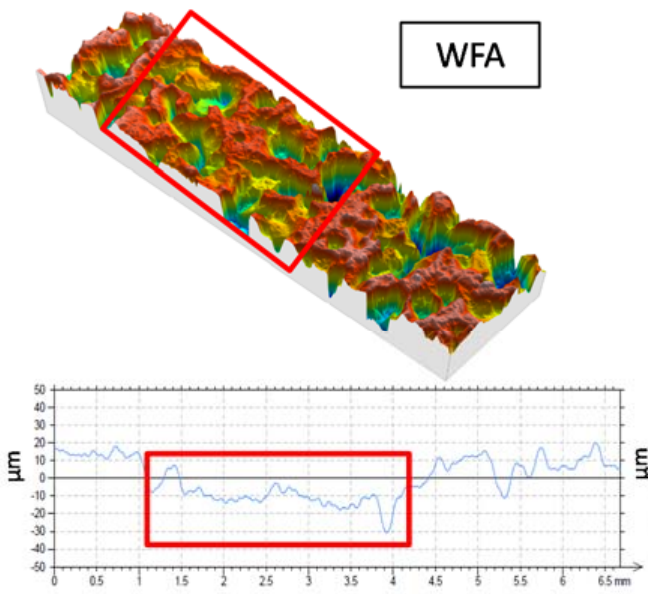

(a)
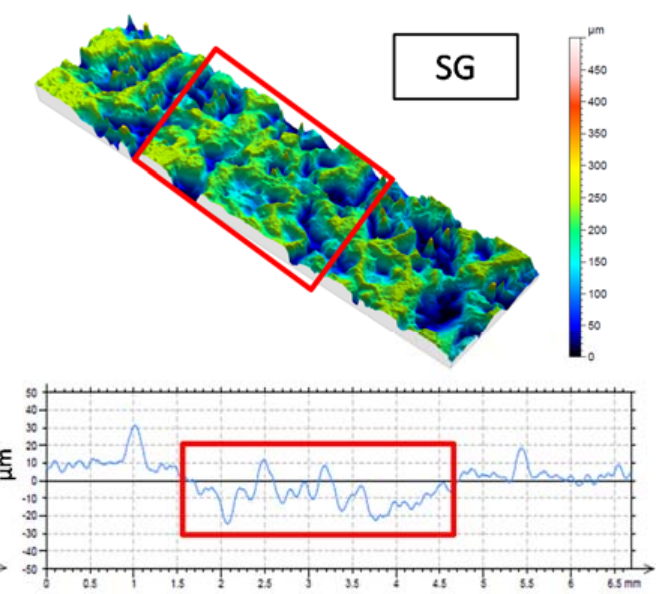

(b)

Figure 6. 3D wheel surface digitalization and envelope of filtered superimposed profiles for (a) WFA and (b) SG alumina.

To quantify the real contact area, the groove depth is needed. For each abrasive grain structure, different depths are measured. Thus, the depth at which the real contact area is obtained is different for each disk. As previously explained, a reference plane is defined for each just dressed surface. From the reference plane, slices are made of the topography at wear depth. The apparent pin area is $15 \mathrm{~mm}^{2}$ in the case of WFA Figure 7a, with a real contact area of $29.33 \pm 1.86 \%, 4.4 \mathrm{~mm}^{2}$ and for SG alumina this is $22.43 \pm 0.99 \%, 3.36 \mathrm{~mm}^{2}$ Figure $7 \mathrm{~b}$. The real contact area of SG alumina is slightly lower than WFA due to the sharper surface.

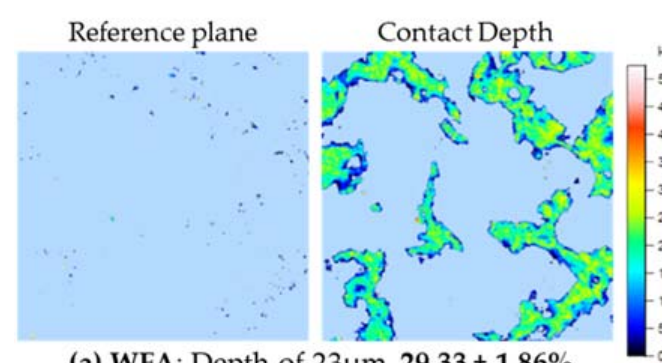

(a) WFA: Depth of $23 \mu \mathrm{m}, 29.33 \pm 1.86 \%$

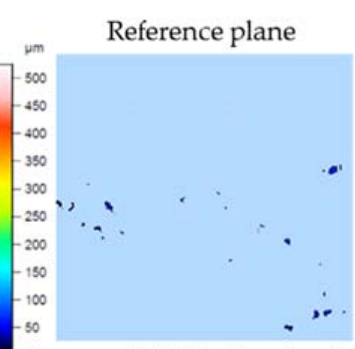

(b) SG: Depth of $17 \mu \mathrm{m}, 22.43 \pm 0.99 \%$

Figure 7. Real contact area quantification from wear depth. Reference plane and contact depth slices for (a) WFA and (b) SG alumina. 
With regard to contact conditions, in Figure 8 both the real contact pressure and friction coefficient is shown. Lower real contact pressures are reached for WFA than for SG alumina-approximately 35\% higher for SG alumina. Two effects are responsible for these dissimilarities. On the one hand higher real contact area values are measured on WFA, due to the abrasive grain structure; the dressed SG surface is sharper than that of the WFA. On the other hand, normal forces reached during the tests are approximately $16 \%$ lower for WFA than for SG. During the pin-on-disk tests, of the three wear mechanisms that take place during the contact, rubbing and ploughing are the most relevant. However, for SG abrasive grains, the sharper surface implies that the cutting edges are more sharp than on WFA abrasive grains and hence cutting also takes place, but to a lesser extent than on real grinding tests. The flatter alumina surface obtained for WFA show the absence of cutting edges. The rubbing mechanism in WFA is of higher importance, which is confirmed with the $S_{p k}$ parameter comparing the effect of the wear, $S_{p k}$ decrease on worn surface. Therefore, rubbing increases the contact temperature and hence the pin temperature. Hardened steel pin becomes soft and it is worn more quickly than in the case of SG alumina. The reached force is imposed for the pneumatic cylinder and the material softening leads to a lower contact force. Furthermore, high temperatures are reached on the pin material, which explains the high wear values reached on both disks in a very short contact time.
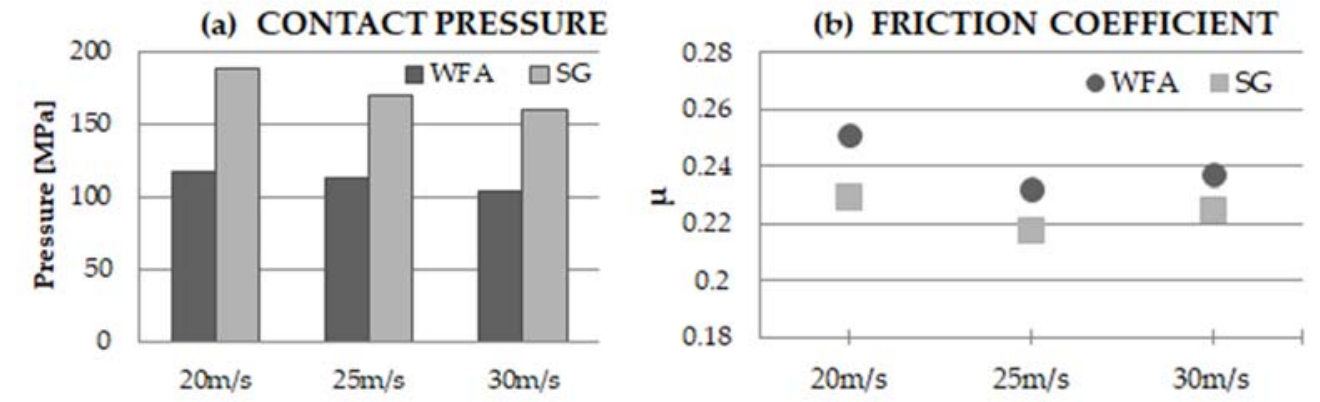

Figure 8. (a) Real contact pressure variation and (b) friction coefficient variation with sliding speed for WFA and SG alumina.

Analyzing the real pressure values, in both crystalline structures the real contact area decreases with $v_{s}$. For SG alumina, the real contact pressure increases from $190 \mathrm{MPa}$ for $v_{s}=20 \mathrm{~m} / \mathrm{s}$ and $160 \mathrm{MPa}$ for $v_{s}=30 \mathrm{~m} / \mathrm{s}$. Thus, for a lower sliding speed, higher real contact pressure is obtained. In this regard, Klocke [17] obtained pressures of approximately 0.5-1.5 GPa at a sliding speed of $2 \mathrm{~m} / \mathrm{s}$. In the case of this study, the sliding speed is at least 10 times higher, and close to that observed during the grinding process, whilst high values of real pressure values are obtained. Therefore, the obtained results on pin-on-disk tribometer can be readily extrapolated to the grinding process, and are useful for characterizing abrasive grain behavior under controlled real contact conditions.

With regard to the friction coefficient, values of between 0.21 and 0.25 are maintained, being slightly lower for SG alumina. On grinding tests carried out in previous work [13], the obtained friction coefficient was in the range of $0.33-0.37$. This difference is primarily due to the wear mechanisms that occur during contact. As previously explained, in the case of the grinding process, cutting, ploughing, and rubbing are involved. In contrast, in the case of pin-on-disk tests, the effect of cutting is minimized and ploughing and rubbing are the main wear types.

\section{Conclusions}

On the basis of the work described here, the following conclusions can be drawn:

- An original tribometer is presented for the analysis of the behavior of abrasive grains in the grinding processes. The achieved contact conditions are near to those of the real process, indicating that the results can be applied to the design of industrial grinding wheels. 
- Grinding contact conditions are imposed and meticulously controlled on the tests carried out in the tribometer with the aim of distinguishing wear behavior of two types of alumina crystalline structure: WFA and SG alumina.

- Due to the heavy conditions in the contact and the small pin area, the theoretical forces are not achieved and the influence of imposed pneumatic pressure is negligible. Only the influence of sliding speed on the test results is taken into account.

- $\quad$ Lower sliding speed leads to higher contact forces regardless of the alumina studied. Moreover, a lower real contact area is measured on SG alumina. Therefore, real contact pressure decrease with sliding speed, from $20 \mathrm{~m} / \mathrm{s}$ to $30 \mathrm{~m} / \mathrm{s}$ a decrease of $15 \%$ is measured. Extrapolating the influence of $v_{s}$ to the grinding process, it is concluded that higher cutting speed implies lower real contact pressure on abrasive grains.

- $\quad$ For the studied sliding speed range, $v_{s}$ do not present a significant influence on abrasive grain wear. However, the influence of the crystalline structure of abrasive grains is appreciable both on the depth of wear and the appearance of the worn surface. WFA presents a $23 \mu \mathrm{m}$ of wear depth whilst SG presents a wear depth of $17 \mu \mathrm{m}$. Moreover, the SG worn surface is sharper than the WFA worn part.

- With respect to the friction coefficient, the values reached on pin-on-disk tests vary from 0.21 to 0.25 . However, on grinding tests these values are higher, from 0.33 to 0.37 . These differences are due to the wear mechanisms that happen on contact. In the case of grinding tests, cutting appears to be more significant than rubbing and ploughing. In contrast, during tribological tests rubbing and ploughing are predominant.

- The presented device appears to be suitable for the analysis of the behavior of abrasive grains in the grinding process, suggesting that this could be a useful industrial tool for the design of grinding wheels.

Author Contributions: L.G. performed the experiments and wrote the paper; I.P. analyzed the data and carried out disk topographies; J.A.S. designed the experiments and supervised the work, and B.I. revised the article.

Acknowledgments: The authors gratefully acknowledge the funding support received from the Spanish Ministry of Economy and Competitiveness and the FEDER operation program for funding the project "Scientific models and machine-tool advanced sensing techniques for efficient machining of precision components of Low Pressure Turbines" (DPI2017-82239-P). Funding support was also received from the contracting call for the training of research staff in UPV/EHU 2016, of Vice-rectorate of research to develop this project.

Conflicts of Interest: The authors declare no conflict of interest. The founding sponsors had no role in the design of the study; in the collection, analyses, or interpretation of data; in the writing of the manuscript, and in the decision to publish the results.

\section{Abbreviations}

$\begin{array}{lll}\mathrm{a}_{\mathrm{d}} & {[\mu \mathrm{m}]} & \text { Dressing Depth } \\ \% A & {[-]} & \text { Percentage of area corresponding to wear flat } \\ \mathrm{SG} & {[-]} & \text { Sintered Sol Gel Alumina } \\ S_{k} & {[\mu \mathrm{m}]} & \text { Core roughness depth } \\ S_{p k} & {[\mu \mathrm{m}]} & \text { Reduced peak height } \\ S_{m r 1} & {[\%]} & \text { Peak material proportion } \\ v_{d} & {[\mathrm{~mm} / \mathrm{min}]} & \text { Dresser speed } \\ v_{s} & {[\mathrm{~m} / \mathrm{s}]} & \text { Sliding speed } \\ \text { WFA } & {[-]} & \text { White Fused Alumina }\end{array}$




\section{References}

1. Oliveira, J.F.G.; Silva, E.J.; Guo, C.; Hashimoto, F. Industrial challenges in grinding. CIRP Ann. Manuf. Technol. 2009, 58, 663-680. [CrossRef]

2. Rowe, W.B. Principles of Modern Grinding Technology, 1st ed.; Elsevier: New York, NY, USA, 2009; ISBN 978-0-8155-2018-4.

3. Nadolny, K. State of the art in production, properties and applications of the microcrystalline sintered corundum abrasive grains. Int. J. Adv. Manuf. Technol. 2014, 74, 1445-1457. [CrossRef]

4. Marinescu, I.D.; Hitchiner, M.P.; Uhlmann, E.; Inasaki, I. Handbook of Machining with Grinding Wheels; Taylor \& Francis Group: Abingdon, UK, 2006; ISBN 9781574446715.

5. Marinescu, I.D.; Rowe, W.B.; Dimitrov, B.; Inasaki, I. Tribology of Abrasive Machining Processes; Elsevier: New York, NY, USA, 2004; ISBN 970815514909.

6. Barth, S.; Klocke, F. Influence of the grinding wheel topography on the thermo-mechanical stress collective in grinding. Inventions 2017, 2, 34. [CrossRef]

7. Lachance, S.; Bauer, R.; Warkentin, A. Application of region growing method to evaluate the surface condition of grinding wheels. Int. J. Mach. Tools Manuf. 2004, 44, 823-829. [CrossRef]

8. Vidal, G.; Ortega, N.; Bravo, H.; Dubar, M.; Gonzalez, H. An analysis of electroplated cBN grinding wheel wear and conditioning during creep feed grinding. Metals 2018, 8, 350. [CrossRef]

9. Leach, R. Characterisation of Areal Surface Texture; Springer: Berlin, Germany, 2013; ISBN 9783642364570.

10. Malkin, S.; Cook, N.H. The wear of grinding wheels. Part 1: Attritious wear. J. Eng. Ind. 1971, 93, 1120-1128. [CrossRef]

11. Nadolny, K. Wear phenomena of grinding wheels with sol-gel alumina abrasive grains and glass-ceramic vitrified bond during internal cylindrical traverse grinding of $100 \mathrm{Cr} 6$ steel. Int. J. Adv. Manuf. Technol. 2015, 77, 83-98. [CrossRef]

12. Yu, T.; Bastawros, A.F.; Chandra, A. Experimental and modeling characterization of wear and life expectancy of electroplated CBN grinding wheels. Int. J. Mach. Tools Manuf. 2017, 121, 70-80. [CrossRef]

13. Godino, L.; Pombo, I.; Sanchez, J.A.; Alvarez, J. On the development and evolution of wear flats in microcrystalline sintered alumina grinding wheels. J. Manuf. Process. 2018, 32, 494-505. [CrossRef]

14. Chen, Z.Z.; Xu, J.H.; Ding, W.F.; Cheng, Z.; Fu, Y.C. High speed grinding of nickel-based superalloy with single diamond grit. Adv. Mater. Res. 2011, 325, 140-146. [CrossRef]

15. Liu, Q.; Roy, A.; Tamura, S.; Matsumura, T.; Silberschmidt, V.V. Micro-cutting of single-crystal metal: finite-element analysis of deformation and material removal. Int. J. Mech. Sci. 2016, 118, 135-143. [CrossRef]

16. Ravikiran, A.; Pramila Bai, B.N. High Speed sliding of $\mathrm{Al}_{2} \mathrm{O}_{3}$ pins against an En-24 steel disc. Wear 1993, 162-164, 296-304. [CrossRef]

17. Mayer, J.; Engelhorn, R.; Bot, R.; Weirich, T.E.; Herwartz, C.; Klocke, F. Wear characteristics of second-phase-reinforced sol-gel corundum abrasives. Acta Mater. 2006, 54, 3605-3615. [CrossRef]

18. Lou, S.; Jiang, X.; Scott, P.J. Application of the morphological alpha shape method to the extraction of topographical features from engineering surfaces. Measurement 2013, 46, 1002-1008. [CrossRef]

(C) 2018 by the authors. Licensee MDPI, Basel, Switzerland. This article is an open access article distributed under the terms and conditions of the Creative Commons Attribution (CC BY) license (http://creativecommons.org/licenses/by/4.0/). 